This item was submitted to Loughborough's Research Repository by the author.

Items in Figshare are protected by copyright, with all rights reserved, unless otherwise indicated.

\title{
Lubrication analysis and sub-surface stress field of an automotive differential hypoid gear pair under dynamic loading
}

PLEASE CITE THE PUBLISHED VERSION

http://dx.doi.org/10.1177/0954406215608893

\section{PUBLISHER}

Sage (@ IMechE)

VERSION

AM (Accepted Manuscript)

\section{PUBLISHER STATEMENT}

This work is made available according to the conditions of the Creative Commons Attribution-NonCommercialNoDerivatives 4.0 International (CC BY-NC-ND 4.0) licence. Full details of this licence are available at: https://creativecommons.org/licenses/by-nc-nd/4.0/

\section{LICENCE}

CC BY-NC-ND 4.0

\section{REPOSITORY RECORD}

Paouris, Leonidas I., Stephanos Theodossiades, Miguel De la Cruz, Homer Rahnejat, Adam Kidson, Gregory Hunt, and William Barton. 2019. "Lubrication Analysis and Sub-surface Stress Field of an Automotive Differential Hypoid Gear Pair Under Dynamic Loading”. figshare. https://hdl.handle.net/2134/19454. 


\title{
Lubrication analysis and sub-surface stress field of an automotive differential hypoid gear pair under dynamic loading
}

\author{
L.I. Paouris ${ }^{1}$, S. Theodossiades ${ }^{1 *}$, M. De la Cruz ${ }^{1}$, H. Rahnejat ${ }^{1}$, A. Kidson ${ }^{2}$, G. Hunt ${ }^{2}$ and W. Barton ${ }^{2}$ \\ ${ }^{1}$ Wolfson School of Mechanical and Manufacturing Engineering, Loughborough University, \\ Loughborough, UK \\ ${ }^{2}$ Applied Sciences Department, Lubrizol Ltd., Hazelwood, Derbyshire, UK \\ *Corresponding Author: S.Theodossiades@lboro.ac.uk
}

\begin{abstract}
Film thickness and sub-surface stress distribution in a highly loaded automotive differential hypoid gear pair are examined. A 4-Degree of Freedom (DoF) torsional gear dynamics model, taking into account the torsional stiffness of the pinion and the gear shafts, is used in order to evaluate the contact load, the surface velocities and the contact radii of curvature of the mating teeth during a full meshing cycle. The torsional gear dynamics model takes into account both the geometric non-linearities of the system (backlash non-linearity) as well as the time varying properties (contact radii, meshing stiffness) and the internal excitations caused by geometrical imperfections of the teeth pair (static transmission error). The input torque used for the study of the film thickness and the sub-surface stress distribution corresponds to the region after the main resonance, where no teeth separation occurs. The contact conditions predicted by the gear dynamics are used as the input for the elastohydrodynamic elliptical point contact analysis. The lubricant film thickness and the corresponding pressure and surface traction distributions are obtained quasi-statically using the output load of the dynamic gear pair model. The variation of the induced sub-surface stress field is determined throughout a meshing cycle. Based on the sub-surface reversing orthogonal shear stresses, marginal differences occur when the viscous shear on the conjunctional surfaces are taken into account, which are mainly influenced by the applied pressure distribution. The numerical prediction of lubricant film thickness agrees reasonably well with that predicted using the well-established extrapolated oil film thickness formulae reported in the literature.
\end{abstract}

\section{Keywords:}

Hypoid gears, Dynamic analysis, elastohydrodynamic lubrication, sub-surface stress field

$\begin{array}{ll}\text { Nomenclature } & \\ a & \text { road inclination angle (degrees) } \\ a_{h} & \text { length of the semi-major axis of the contact ellipse }(\mathrm{m}) \\ A_{f} & \text { frontal area of the vehicle }\left(\mathrm{m}^{2}\right) \\ b & \text { half backlash in meshing teeth pairs }(\mathrm{m}) \\ b_{h} & \text { length of the semi-minor axis of the contact ellipse }(\mathrm{m}) \\ c & \text { damping coefficient per meshing teeth pair }(\mathrm{Ns} / \mathrm{m}) \\ {[\mathrm{C}]} & \text { damping matrix of the linearized lumped parameter dynamic model } \\ c_{a} & \text { aerodynamic drag coefficient }(-) \\ c_{t 1} & \text { torsional damping coefficient of the ring gear shaft }(\mathrm{Nms} / \mathrm{rad}) \\ c_{t 2} & \text { torsional damping coefficient of the pinion shaft }(\mathrm{Nms} / \mathrm{rad}) \\ e & \text { time varying static (unloaded) transmission error of the meshing teeth }(\mathrm{m}) \\ E & \text { Young's modulus of elasticity of contiguous surfaces }(\mathrm{Pa}) \\ E_{r} & \text { reduced modulus of elasticity of the contacting pairs } E_{r}=E /\left(1-\mathrm{v}^{2}\right)(\mathrm{N})\end{array}$




\begin{tabular}{|c|c|}
\hline$f$ & backlash function $(m)$ \\
\hline$f_{r}$ & coefficient of rolling resistance $(-)$ \\
\hline$g$ & gravitational acceleration $\left(\mathrm{m} / \mathrm{s}^{2}\right)$ \\
\hline$g\left(x, y, R_{z x}, R_{z y}\right)$ & teeth pair local geometry for the elastic film thickness function $(m)$ \\
\hline$G$ & Chittenden-Dowson dimensionless material parameter $\left(G=\alpha_{0} E_{r}\right)(-)$ \\
\hline$G^{*}$ & dimensionless materials' parameter $\left(G^{*}=\alpha_{0} E_{r}\right)(-)$ \\
\hline$G_{e}$ & Greenwood's elastic parameter $(-)$ \\
\hline$G_{v}$ & Greenwood's viscous parameter $(-)$ \\
\hline$h$ & elastohydrodynamic (EHL) film thickness $(m)$ \\
\hline$h_{0}$ & rigid body gap $(m)$ \\
\hline$I_{g}$ & ring gear's mass moment of inertia $\left(\mathrm{kgm}^{2}\right)$ \\
\hline$I_{p}$ & pinion’s mass moment of inertia $\left(\mathrm{kgm}^{2}\right)$ \\
\hline$I_{s}$ & ring gear shaft's mass moment of inertia $\left(\mathrm{kgm}^{2}\right)$ \\
\hline$I_{w}$ & pinion shaft's mass moment of inertia $\left(\mathrm{kgm}^{2}\right)$ \\
\hline$[K]$ & stiffness matrix of the linearized lumped parameter dynamics model \\
\hline$k_{m}$ & time varying meshing stiffness $(\mathrm{N} / \mathrm{m})$ \\
\hline$k_{t}$ & torsional stiffness of the ring gear and the pinion shafts $(\mathrm{Nm} / \mathrm{rad})$ \\
\hline$[M]$ & mass matrix of the linearized lumped parameter dynamics model \\
\hline$m_{v}$ & mass of the vehicle $(\mathrm{kg})$ \\
\hline$N_{g}$ & number of ring gear teeth $(-)$ \\
\hline$N_{p}$ & number of pinion teeth $(-)$ \\
\hline$p$ & pressure $(P a)$ \\
\hline$P_{h}$ & mean Hertzian contact pressure $(P a)$ \\
\hline$R_{e}$ & effective radius of curvature along the direction of lubricant entrainment $(-)$ \\
\hline$R_{g}$ & principal time varying contact radius of the ring gear $(m)$ \\
\hline$R_{p}$ & principal time varying contact radius of the pinion $(m)$ \\
\hline$R_{S}$ & effective radius of curvature along the side leakage direction $(-)$ \\
\hline$R_{z x}$ & time varying contact radius of curvature along the direction of entraining motion $(\mathrm{m})$ \\
\hline$R_{z y}$ & time varying contact radius of curvature along the side leakage direction $(\mathrm{m})$ \\
\hline$r_{w}$ & tyre radius $(m)$ \\
\hline$t$ & time $(s)$ \\
\hline$T_{s}$ & constant input torque at the ring gear shaft $(\mathrm{Nm})$ \\
\hline$T_{w}$ & resistive torque at the pinion shaft $(\mathrm{Nm})$ \\
\hline$U$ & lubricant entraining velocity $\left(U=\left(U_{1}+U_{2}\right) / 2\right)(\mathrm{m} / \mathrm{s})$ \\
\hline$U^{*}$ & dimensionless speed parameter $\left(U^{*}=U \eta / E_{r} R_{z x}\right)(-)$ \\
\hline$U_{1}$ & pinion tooth surface velocity along the direction of entraining motion $(\mathrm{m} / \mathrm{s})$ \\
\hline$U_{2}$ & gear tooth surface velocity along the side leakage direction $(\mathrm{m} / \mathrm{s})$ \\
\hline$U_{e}$ & Chittenden-Dowson dimensionless speed parameter $\left(U_{e}=\eta_{0} U / E_{r} R_{e}\right)(-)$ \\
\hline
\end{tabular}




$\begin{array}{ll}u_{v} & \text { vehicle cruising velocity }(\mathrm{m} / \mathrm{s}) \\ v & \text { Poisson's ratio }(-) \\ V_{1} & \text { pinion tooth surface velocity along the side leakage direction }(\mathrm{m} / \mathrm{s}) \\ V_{2} & \text { gear tooth surface velocity along the side leakage direction }(\mathrm{m} / \mathrm{s}) \\ W & \text { flank contact load }(\mathrm{N}) \\ W^{*} & \text { dimensionless load parameter }\left(W^{*}=W / E_{r} R_{z x}{ }^{2}\right)(-) \\ W_{e} & \text { Chittenden-Dowson dimensionless load parameter }\left(U_{e}=W / E_{r} R_{e}{ }^{2}\right)(-) \\ W_{E H L} & \text { elastohydrodynamic contact reaction }(N) \\ x & \text { dynamic (loaded) transmission error }(m) \\ X_{i n, f / s} & \text { dimensionless location of the fully-flooded/starved boundary position }(-) \\ Z & \text { sub-surface direction }(m) \\ Z & \text { Roeland's piezo-viscosity coefficient }\end{array}$

\section{Greek Symbols}

$\begin{array}{ll}\alpha & \text { damping matrix proportionality coefficient } \\ \alpha_{0} & \text { pressure-viscosity coefficient }\left(\mathrm{Pa}^{-1}\right) \\ \beta & \text { damping matrix proportionality coefficient } \\ \delta & \text { local elastic deflection of the mating surfaces of teeth pair }(\mathrm{m}) \\ \eta & \text { low shear dynamic viscosity of the lubricant }(\mathrm{Pa} \cdot \mathrm{s}) \\ \eta_{0} & \text { low shear dynamic viscosity of the lubricant at atmospheric pressure }(\mathrm{Pa} \cdot \mathrm{s}) \\ \rho & \text { density of lubricant }\left(\mathrm{kg} / \mathrm{m}^{3}\right) \\ \rho_{a i r} & \text { density of air }\left(\mathrm{kg} / \mathrm{m}^{3}\right) \\ \sigma_{e} & \text { equivalent stress for the subsurface stress distribution }(\mathrm{Pa}) \\ \sigma_{x} & x x \text { component of the sub-surface stress field }(\mathrm{Pa}) \\ \sigma_{y} & y y \text { component of the sub-surface stress field }(\mathrm{Pa}) \\ \varsigma & \text { load relaxation parameter }(-) \\ \tau_{x z} & x y \text { component of the sub-surface stress field }(\mathrm{Pa}) \\ \varphi_{g} & \text { ring gear rotational angle }(\mathrm{rad}) \\ \varphi_{p} & \text { pinion rotational angle }(\mathrm{rad}) \\ \varphi_{s} & \text { ring gear shaft rotational angle }(\mathrm{rad}) \\ \varphi_{w} & \text { pinion shaft rotational angle }(\mathrm{rad})\end{array}$

\section{Introduction}

Hypoid gear pairs are widely used in modern automotive differentials. They transfer the applied engine torque to the driven axle and subsequently to the wheels. The applied torque is usually quite high with a gear ratio selected to overcome the rolling resistance on the wheels. Measures used to palliate the effect of high loads, which are usually combined with high sliding velocities of the meshing teeth, are focused on teeth modification ${ }^{1-3}$ in order to minimize the fluctuations in the contact load of the meshing teeth pairs. At the same time lubrication is essential to avoid seizure or excessive wear due to the high flank traction. The combination of 
reduced vibration and high transmission efficiency (thus reduced frictional power loss) is thus highly desirable. Mohammadpour et al. ${ }^{4}$ have shown that these requirements sometimes conflict. For example, reduction in flank friction can lead to excessive system vibration since some of the transferred energy is usually consumed by friction. Therefore, any analysis should integrate system dynamics with tribological performance. The latter should include the determination of regime of lubrication for a range of operating conditions, as well as ensuring the structural integrity of contacting surfaces under the extreme conditions encountered. This necessitates the determination of sub-surface stress field to avoid onset of inelastic deformation ${ }^{5}$.

The current literature on hypoid gears and lubrication can be classified into three different categories; each one focusing on a different aspect of analysis, which when combined can result in a better understanding of the problem. One category is focused on the geometry; the global and local (contact) deflection of hypoid gear

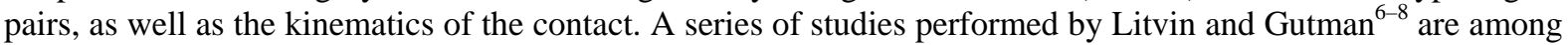
the first who attempted to predict the resultant tooth surface geometry of hypoid gear pairs as a function of the machining parameters. This approach is known as tooth contact analysis (TCA), which yields the necessary geometrical (principal radii of contacting pairs contact footprint) and kinematic data (surface velocities) between the mating surfaces. These data are required for the combined solution of Reynolds and elasticity potential equations. Other required data comprise the share of the total contact load between the meshing teeth, which includes the effects of applied torque, as well as the resistive torque applied on the driven axle and finally the inertial effects. Therefore, a detailed dynamic analysis is combined with the aforementioned integrated study.

Unlike other gearing configurations, and due to the complexity of the contacting geometry of hypoid pairs and the need for combined dynamics and tribological solution, there has been a relative dearth of representative analysis for such gears. In particular, the contact of hypoid gear teeth pairs yields an elliptical point contact footprint with significant side leakage of lubricant from the contact domain, a point not often taken into account by the majority of the previous contributions. These studies have shown thin lubricant films, resulting in mixed elastohydrodynamic conditions. An analytical solution for such conditions including thermal effects was presented by Karagiannis et al. ${ }^{9}$, who employed Grubin's lubricant film thickness equation ${ }^{10}$ for the general case of elliptical point contact geometry, modified to include the effect of side leakage from the contact conjunction, proposed by Gohar ${ }^{11}$. In another analytical contribution Kolivand and Kahraman ${ }^{12}$ provided a regressed equation for friction, based on mixed elastohydrodynamic conditions and non-Newtonian shear of the thin lubricant film using the line contact approximation for elliptical contact footprints with a high aspect ratio. Simon $^{13}$ presented a thermo-elastohydrodynamic analysis of hypoid gear pairs with elliptical point contact geometry but with no side leakage flow. Recent studies by $\mathrm{Li}$ and Kahraman ${ }^{14}$ and $\mathrm{Li}^{15}$ have provided insight into the tribodynamic response of spur gear pairs. Direct comparisons of the power loss between quasi-static and fully coupled tribodynamic models were performed, highlighting the influence of system dynamics. In a series of papers Mohammadpour et al. ${ }^{4,16,17}$ provided full numerical solutions for hypoid gear pairs under isothermal elastohydrodynamic, mixed isothermal non-Newtonian and analytical thermo-mixed non-Newtonian elastohydrodynamic conditions. In the most recent of these contributions, Mohammadpour et al. ${ }^{4}$ introduced a 2 DOF dynamics' model of a vehicular differential hypoid gear pair as a multi-body system. They also took into account the aerodynamic drag, as well as the rolling resistance on the wheels of the driven axle. Their gear dynamics model was based on the one recommended by Karayiannis et $\mathrm{al}^{9}$, although an elliptical point contact EHL numerical solver was employed, yielding more accurate predictions of the EHL film thickness. However, they did not include the relatively high, but finite torsional stiffness of the supporting shafts of the differential. These are included in the extended gear dynamics model presented here.

Furthermore, a full numerical solution of the lubricated contacts of gear teeth is presented by taking into account the dynamic response of the gear pair. Using system dynamics as input conditions into the EHL model, yields more representative predictions for the EHL film thickness and the conjunctional lubricant pressure distribution. Finally, the influence of the EHL pressure distribution on the subsurface stress distribution in the teeth pair conjunction is studied by implementing a sub-surface stress solver. Predictions of the subsurface stress field in hypoid gear pairs under the combined influence of gear dynamics and the elastohydrodynamic (EHD) lubrication effects yields an integrated study of their performance, which has not hitherto been reported in literature. 


\section{Theory}

Gear dynamics

A 4 DoF torsional gear dynamics solver is employed, taking into account the finite torsional stiffness of the pinion and the gear shafts. Equations (1) - (4) are used to describe the torsional inertial dynamics of the system. Similar formulations have been proposed by Lim and his co-workers ${ }^{18,19}$.

$$
\begin{aligned}
& \ddot{\varphi}_{s}=\frac{1}{I_{s}}\left[-k_{t}\left(\varphi_{s}-\varphi_{p}\right)-c_{t 1}\left(\dot{\varphi}_{s}-\dot{\varphi}_{p}\right)+T_{s}\right] \\
& \ddot{\varphi}_{p}=\frac{1}{I_{p}}\left[-R_{p}\left(k_{m} f+c \dot{x}\right)+k_{t}\left(\varphi_{s}-\varphi_{p}\right)+c_{t 1}\left(\dot{\varphi}_{s}-\dot{\varphi}_{p}\right)\right] \\
& \ddot{\varphi}_{g}=\frac{1}{I_{g}}\left[R_{g}\left(k_{m} f+c \dot{x}\right)-k_{t}\left(\varphi_{g}-\varphi_{w}\right)-c_{t 2}\left(\dot{\varphi}_{g}-\dot{\varphi}_{w}\right)\right] \\
& \ddot{\varphi}_{w}=\frac{1}{I_{w}}\left[k_{t}\left(\varphi_{g}-\varphi_{w}\right)+c_{t 2}\left(\dot{\varphi}_{g}-\dot{\varphi}_{w}\right)-T_{w}\right]
\end{aligned}
$$

The lumped parameter torsional gear dynamics model, described by equations (1) - (4), is illustrated in figure 1 . The supporting shafts of the pinion and the gear have been replaced by elements which characterize their rotational inertia and their torsional stiffness and damping. The pinion and the ring gear are represented by two rigid disks with finite rotational inertia, whereas the flank stiffness and damping, as well as the backlash, are formulated as an element which is attached circumferentially to the pinion and the gear inertias.

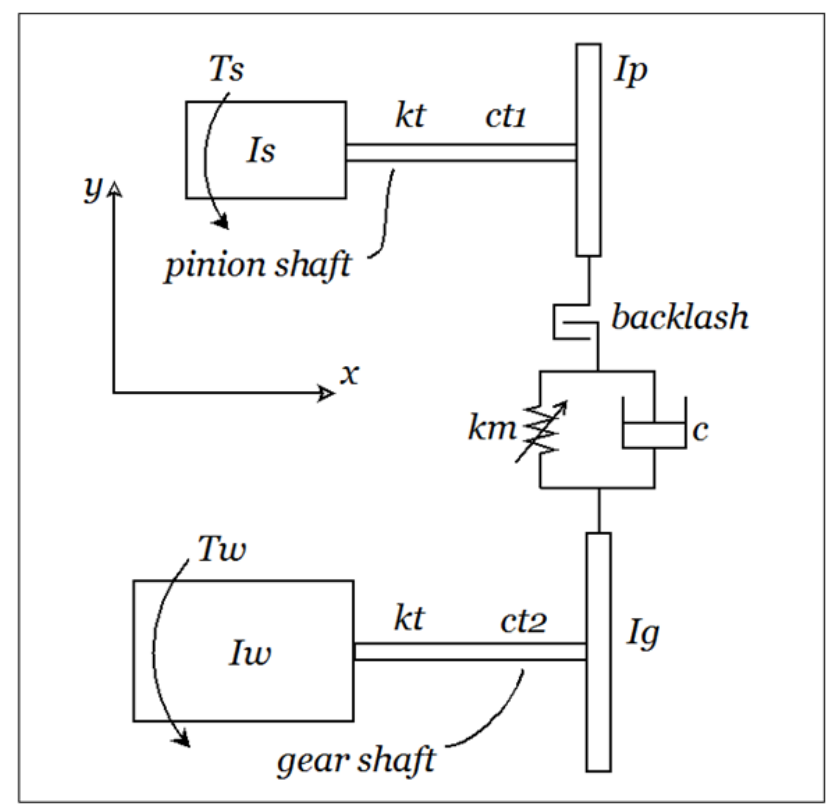

Figure 1: Torsional gear dynamics lamped parameter model

The values for structural damping are calculated based on the assumption that the system damping is proportional (i.e. Rayleigh's damping) as recommended by Schwarz and Richardson ${ }^{20}$. For this purpose, all the non-linearities of equations (1) - (4) are removed and a linearised system is used to calculate the damping matrix using:

$$
[C]=\alpha[M]+\beta[K]
$$

The expression for damping, mass and stiffness matrices of the linearised system are given as: 


$$
\begin{aligned}
& {[C]=\left[\begin{array}{cccc}
c_{t 1} & -c_{t 1} & 0 & 0 \\
-c_{t 1} & c R_{p 0}^{2}+c_{t 1} & -c R_{p 0} R_{g 0} & 0 \\
0 & -c R_{p 0} R_{g 0} & c R_{g 0}^{2}+c_{t 2} & -c_{t 2} \\
0 & 0 & -c_{t 2} & c_{t 2}
\end{array}\right]} \\
& {[M]=\left[\begin{array}{cccc}
I_{s} & 0 & 0 & 0 \\
0 & I_{p} & 0 & 0 \\
0 & 0 & I_{g} & 0 \\
0 & 0 & 0 & I_{w}
\end{array}\right]} \\
& {[K]=\left[\begin{array}{cccc}
k_{t} & -k_{t} & 0 & 0 \\
-k_{t} & k_{m 0} R_{p 0}^{2}+k_{t} & -k_{m} R_{p 0} R_{g 0} & 0 \\
0 & -k_{m} R_{p 0} R_{g 0} & k_{m} R_{g 0}^{2}+k_{t} & -k_{t} \\
0 & 0 & -k_{t} & k_{t}
\end{array}\right]}
\end{aligned}
$$

It is assumed that the torsional gear dynamics system examined in the present study is lightly damped. Consequently, the mass proportionality coefficient $\alpha$ can be set to: $\alpha=0$ according to Mostofi ${ }^{21}$. Using the mass and the stiffness matrices of the linearized dynamic system, the natural frequencies are: $\omega_{n 1}=0 \mathrm{rad} / \mathrm{s}$, $\omega_{n 2}=2178 \mathrm{rad} / \mathrm{s}, \omega_{n 3}=7414 \mathrm{rad} / \mathrm{s}$ and $\omega_{n 4}=26500 \mathrm{rad} / \mathrm{s}$. The null value for the first natural frequency is because of the presence of the rigid body rotation. By setting the damping ratio for the $2^{\text {nd }}$ mode shape $\zeta_{2}=0.02$, equation (9) can now be used in order to determine the value of the proportionality constant $\beta$ which appears in equation (5), as:

$$
\zeta_{i}=\frac{\beta \omega_{n i}}{2}
$$

Applying equation (9) for the $2^{\text {nd }}$ mode shape yields: $\beta=1.8365 \cdot 10^{-5} s$. Knowing the value of $\beta$, combined with the calculated values of the rest of the angular natural frequencies, $\omega_{n 3}$ and $\omega_{n 4}$, yields the values of the damping ratio for the rest of the mode shapes $\zeta_{3}$ and $\zeta_{4}$. For this study, $\zeta_{3}=0.0681$ and $\zeta_{4}=0.2433$.

In equations (1) - (4), the backlash function $f$, the dynamic transmission error $x$, and the resistive torque at the gear shaft $T_{w}$ can be calculated, using equations (10) - (12).

$$
\begin{aligned}
& f=\left\{\begin{array}{cc}
x-b & \text { when } x \geq b \\
0 & \text { when }-b<x<b \\
x+b & \text { when } x \leq-b
\end{array}\right. \\
& \dot{x}=R_{p} \dot{\varphi}_{p}-R_{g} \dot{\varphi}_{g}-\dot{e} \\
& T_{w}=r_{w}\left(m_{v} g f_{r} \cos (a)+m_{v} g \sin (a)+c_{a} A_{f} \frac{\rho_{\text {air }}}{2} u_{v}^{2}\right)
\end{aligned}
$$

These equations account for the longitudinal vehicle dynamics, as the rolling resistance acting on the driven wheels and the aerodynamic drag are taken into account. This relationship has been used in the hypoid gear dynamics study of Mohammadpour et al. ${ }^{4}$, as well as in Karagiannis et al. ${ }^{9,22,23}$. The time varying contact characteristics are calculated at each time step, using:

$$
\begin{aligned}
& R_{g}=R_{g 0}+\sum_{i} R_{g s i} \sin \left(i N_{g} \varphi_{g}\right)+\sum_{i} R_{g c i} \cos \left(i N_{g} \varphi_{g}\right) \\
& R_{p}=R_{p 0}+\sum_{i} R_{p s i} \sin \left(i N_{p} \varphi_{p}\right)+\sum_{i} R_{p c i} \cos \left(i N_{p} \varphi_{p}\right) \\
& k_{m}=k_{m 0}+\sum_{i} k_{m s i} \sin \left(i N_{p} \varphi_{p}\right)+\sum_{i} k_{m c i} \cos \left(i N_{p} \varphi_{p}\right) \\
& e=e_{0}+\sum_{i} e_{s i} \sin \left(i N_{p} \varphi_{p}\right)+\sum_{i} e_{c i} \cos \left(i N_{p} \varphi_{p}\right)
\end{aligned}
$$


The above equations correspond to the Fourier expansions of each of the contact data obtained by curve fitting the original TCA results, which have been produced using the commercial software CALYX ${ }^{24}$. The local principal radii of curvature, the contact radius, the static transmission error and the tooth load share factor are calculated for a full meshing cycle. Since their values are a periodic function of the pinion angle, the Fourier series can be used in order to obtain their analytical expression as a function of the pinion angle. The parameters in these equations are expanded for 8 Fourier coefficients. The values of the Fourier coefficients are the same as those used by Mohammadpour et al. ${ }^{25}$ and correspond to a hypoid gear pair with the pertinent data listed in table 1. For the hypoid gear pair examined, the r.m.s. surface roughness is $0.45 \mu \mathrm{m}$. The influence of roughness on lubricant film generation is neglected in the current analysis.

Table 1. Gear pair geometric characteristics.

\begin{tabular}{lcc}
\hline Parameter & Pinion & Gear \\
\hline Teeth Number & 13 & 36 \\
\hline Face Width (mm) & 33.851 & 29.999 \\
Face Angle (deg.) & 29.056 & 59.653 \\
Pitch Angle (deg.) & 29.056 & 59.653 \\
Root Angle (deg.) & 29.056 & 59.653 \\
Spiral Angle (deg.) & 45.989 & 27.601 \\
Pitch Appex (mm) & -9.085 & 8.987 \\
Face Appex (mm) & 1.368 & 10.948 \\
Outer Cone Distance (mm) & 83.084 & 95.598 \\
Offset (mm) & 24.0 & 24.0 \\
Sense (Hand) & Right & Left \\
\hline
\end{tabular}

\section{Elastohydrodynamic conjunction}

In order to estimate the central and minimum lubricant film thickness throughout the meshing cycle, an elliptical point contact EHL solver is developed. Here, it is assumed that the lubricant exhibits Newtonian shear characteristics. Mohammadpour et al. ${ }^{16}$ have shown that this assumption can lead to sufficiently accurate estimations of the film thickness since the lubricant is mostly sensitive to the inlet conditions and it is fairly insensitive to load under elastohydrodynamic conditions. Furthermore, Yang et al. ${ }^{26}$ have shown that whilst inlet shear heating affects the lubricant viscosity and thus viscous friction, its effect upon thin elastohydrodynamic films is fairly insignificant. Therefore, if the inlet shear thinning due to the presence of inlet swirl and reversing flows is neglected, then Newtonian shear characteristics may be assumed. The 2D Reynolds equation (equation (17)) is solved numerically in order to determine the contact lubricant pressure distribution. The contact footprint is assumed to be elliptical with a large aspect ratio. This is mainly due to the crowning of the gear teeth. Thus, a solution of the 2D Reynolds equation is sought:

$$
\frac{\partial}{\partial x}\left[\frac{\rho h^{3}}{\eta} \frac{\partial p}{\partial x}\right]+\frac{\partial}{\partial y}\left[\frac{\rho h^{3}}{\eta} \frac{\partial p}{\partial y}\right]=6\left\{\frac{\partial}{\partial x}\left[\rho h\left(U_{1}+U_{2}\right)\right]+\frac{\partial}{\partial y}\left[\rho h\left(V_{1}+V_{2}\right)\right]+2 \frac{d(\rho h)}{d t}\right\}
$$

The film thickness at any location within the contact domain is calculated according to:

$$
h(x, y)=h_{0}+g\left(x, y, R_{z x}, R_{z y}\right)+\delta(x, y, p)
$$

The localised elastic deflection is obtained through solution of the elasticity potential equation:

$$
\delta(x, y)=\frac{2}{\pi E_{r}} \iint_{A} \frac{p\left(x_{1}, y_{1}\right) d x d y}{\sqrt{\left(x-x_{1}\right)^{2}+\left(y-y_{1}\right)^{2}}}
$$

Finally, the pressure dependence of the low shear dynamic viscosity of the lubricant is given as ${ }^{27}$ :

$$
\eta=\eta_{0} e^{\left(\left(\ln \left(\eta_{0}\right)+9.67\right)\left\{\left(1+5.1 \cdot 10^{-9} p\right)^{Z}-1\right\}\right)}
$$


The piezo-viscosity coefficient introduced in equation (20) can be calculated using equation (21) according to Houpert $^{28}$ :

$$
Z=\frac{\alpha_{0}}{5.1 \cdot 10^{-9}\left\{\ln \left(\eta_{0}\right)+9.67\right\}}
$$

In the present study, a gear oil with dynamic viscosity at atmospheric conditions of $\eta_{0}=0.135 P a$. $s$ and pressure-viscosity coefficient $\alpha_{0}=10^{-8} \mathrm{~Pa}^{-1}$ is employed. The material of the gear teeth in conjunction is steel with $E=210 G P a$ and $v=0.33$. Finally, the compressibility of the lubricant is taken into account by employing the Dowson-Higginson equation ${ }^{29}$ for the density variation with pressure as:

$$
\rho=\rho_{0}\left(1+\frac{0.6 p}{1+1.7 p}\right)
$$

\section{Boundary conditions}

Swift-Stieber ${ }^{30}$ exit boundary conditions are applied, where $x_{\text {out }}$ is the position of lubricant film rupture:

$$
p \geq 0 \text { and }\left.\frac{d p}{d x}\right|_{x=x_{\text {out }}}=\left.\frac{d p}{d y}\right|_{y=y_{\text {out }}}=0
$$

Zero-pressure gradient along the side-leakage direction is also needed in order to maintain the lubricant film continuity along the same direction, since the current analysis takes into account the side-leakage flow as well, which is required for angled flow entrainment analysis. A fully flooded inlet boundary is assumed.

\section{Numerical procedure}

The calculation of the pressure distribution and the lubricant film thickness commences with an initial guess of the conjunctional gap, $h_{0}$. The method of solution is the Effective Influence Newton-Raphson (EIN) method, using a Distributed Line Relaxation algorithm.

Figure 2 illustrates the flowchart which describes the algorithm used in order to solve the EHL problem. The pressure convergence criterion is described by:

$$
\sum_{i} \sum_{j}\left|\frac{p_{i, j}^{n}-p_{i, j}^{n-1}}{p_{i, j}^{n}}\right| \leq 10^{-4}
$$

After pressure convergence is achieved, the load carrying capacity of the EHL conjunction is calculated using equation (25). Since the applied load for the meshing teeth pairs is an input which is obtained from the solution of the gear dynamics model, the convergence of the generated lubricant reaction against the applied load is sought by satisfying equation (26).

$$
\begin{aligned}
& W_{E H L}=\int_{-1.5}^{1.5} \int_{-4}^{2} p(x, y) d x d y \\
& \left|\frac{W-W_{E H L}}{W}\right| \leq 10^{-3}
\end{aligned}
$$

If equation (26) is not satisfied, the conjunctional gap $h_{0}$ is altered according to equation (27) and the entire procedure is repeated.

$$
h_{0}^{k}=h_{0}^{k-1}\left(\frac{W_{E H L}}{W}\right)^{\varsigma}
$$




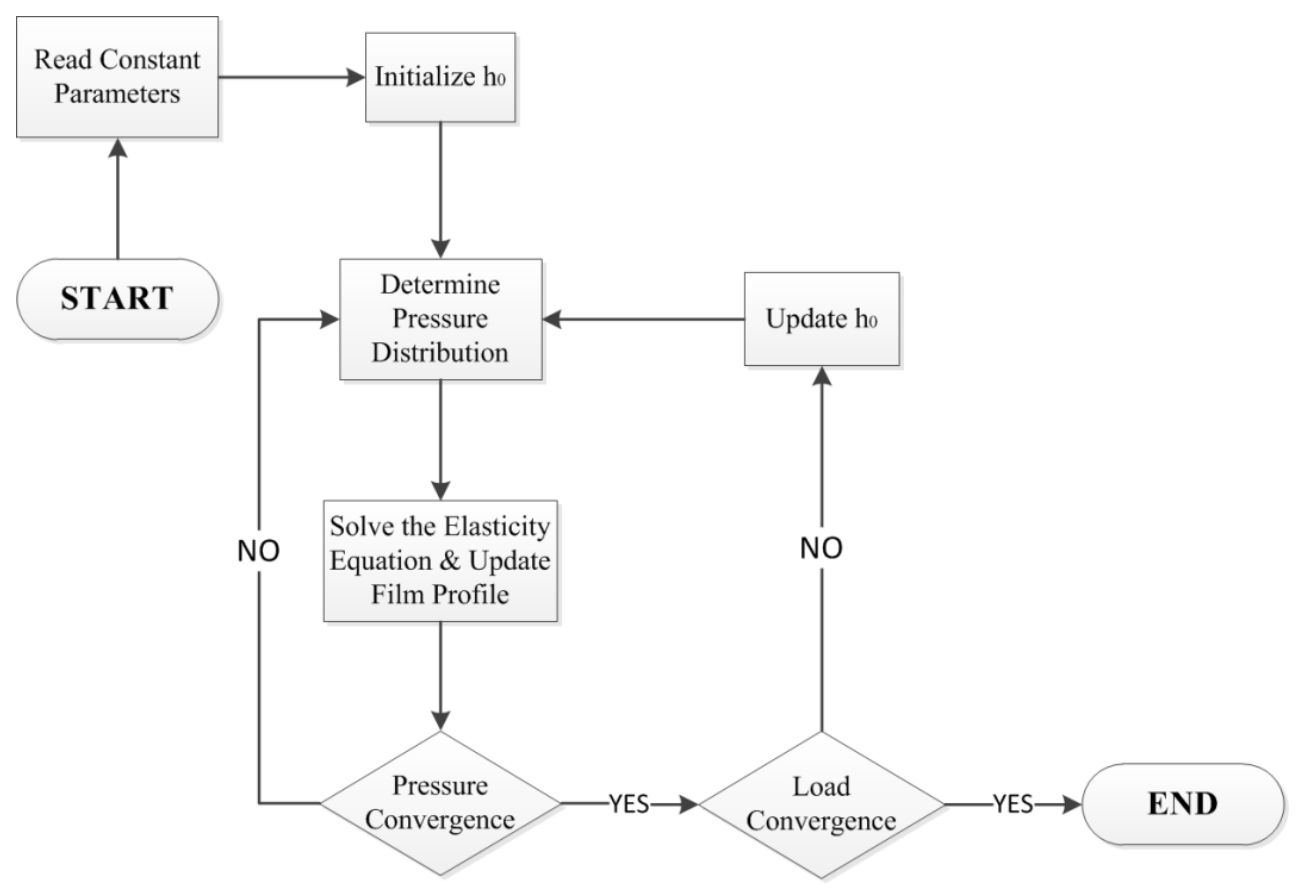

Figure 2: Flowchart of the EHL solver

In the majority of the calculations, a computational mesh of $250 \times 200$ points is used to achieve load convergence for highly loaded contacts. The computational domain extends to a distance of $4 b_{h}$ (with $b_{h}$ being the half-width of the semi-minor axis of the instantaneous elliptical point contact footprint) from the centre of the contact ellipse, upstream in the direction of inlet and $2 b_{h}$ from the centre of the contact ellipse downstream to the position of lubricant film rupture, $x_{\text {out }}$. Along the side leakage direction, the fluid domain extends to a distance of $1.5 a_{h}$ from the centre of the contact ellipse upstream and downstream of the same direction. Figure 3 illustrates the computational contact domain used in the present analysis.

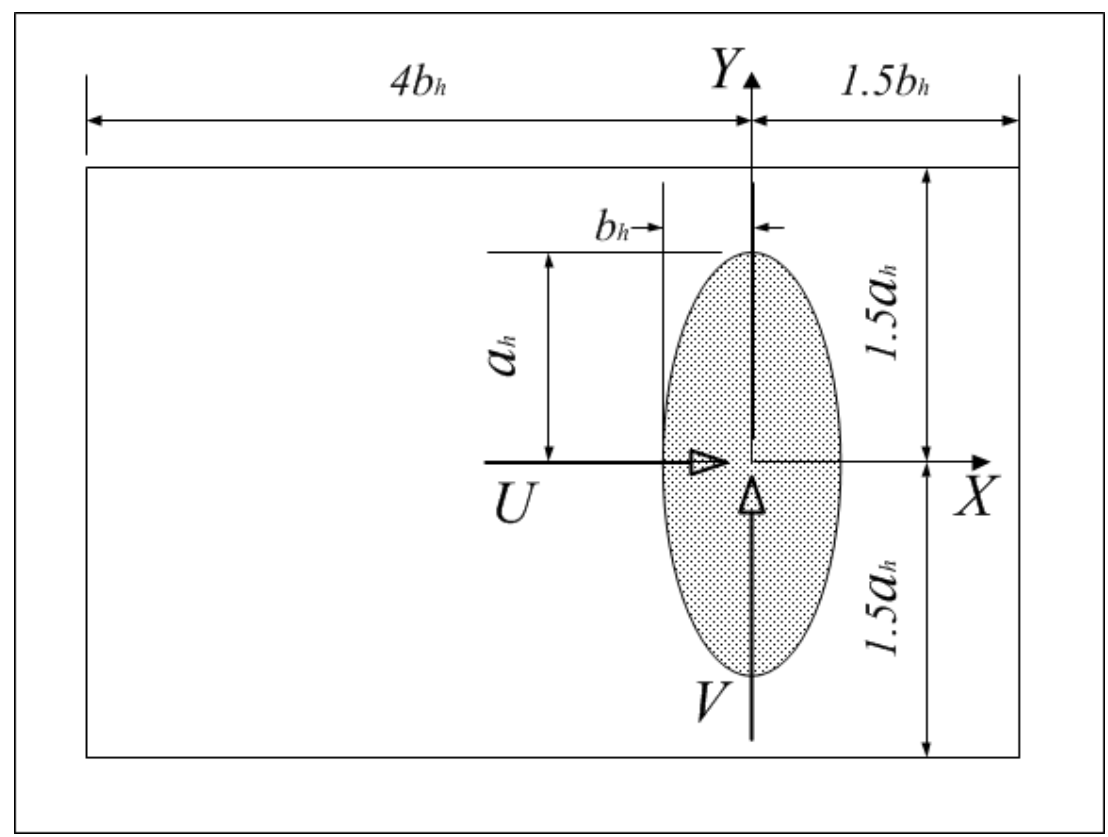

Figure 3: Computational contact domain with the contact dimensions 


\section{Sub-surface stress field}

High contact pressures can lead to localised inelastic/plastic deformation of contacting solids, arising from the generated sub-surface stress field. The yielding phenomenon is referred to as fatigue spalling. Therefore, an important consideration is to ensure the integrity of the contacting solid surfaces under the prevailing conditions. In this paper a semi-analytical method ${ }^{31}$, according to Johnson, is employed, which ignores the variation of the sub-surface stress field in the direction of the side-leakage from the elliptical contact footprint (plane stress condition). However, ideally for elliptical contacts with significant side-leakage flow, a 3dimensional bulk sub-surface stress analysis would be required as highlighted by Johns-Rahnejat ${ }^{32}$ and JohnsRahnejat and Gohar ${ }^{5}$ since the pressures in the lateral direction also affect the stress field in the sub-surface domain. Nevertheless, the 3-dimensional approach is computationally time-intensive, thus the simplified analytical approach is used here in the first instance. Furthermore, with the high ellipticity ratio of the hypoid gear teeth pair contact footprint (of the order of 10-15) this approach essentially satisfies the assumption of line contact conditions. Thus ${ }^{31}$ :

$$
\begin{aligned}
& \sigma_{x}=-\frac{2 z}{\pi} \int_{-4}^{2} \frac{p(w)(x-w)^{2} d w}{\left[(x-w)^{2}+z^{2}\right]^{2}}-\frac{2}{\pi} \int_{-4}^{2} \frac{q(w)(x-w)^{3} d w}{\left[(x-w)^{2}+z^{2}\right]^{2}} \\
& \sigma_{y}=-\frac{2 z^{3}}{\pi} \int_{-4}^{2} \frac{p(w) d w}{\left[(x-w)^{2}+z^{2}\right]^{2}}-\frac{2 z^{2}}{\pi} \int_{-4}^{2} \frac{q(w)(x-w) d w}{\left[(x-w)^{2}+z^{2}\right]^{2}} \\
& \tau_{x z}=-\frac{2 z^{2}}{\pi} \int_{-4}^{2} \frac{p(w)(x-w) d w}{\left[(x-w)^{2}+z^{2}\right]^{2}}-\frac{2 z}{\pi} \int_{-4}^{2} \frac{q(w)(x-w)^{2} d w}{\left[(x-w)^{2}+z^{2}\right]^{2}}
\end{aligned}
$$

The integrals in expressions (28)-(30) are evaluated numerically using the trapezoidal rule. The size of the grid used is 1000 points into the depth of the contacting surfaces, reaching a sub-surface depth of $10 b_{h}$.

\section{Results}

\section{Gear dynamics}

The numerical results from the torsional gear dynamics model are used to calculate the contact load, with the TCA providing the surface velocity of the teeth pairs in their conjunction as well as the local radii of curvature of the contacting point. The values of the input parameters used in the gear dynamics model are listed in table 2. Figure 4 illustrates the Dynamic Transmission Error (DTE) amplitude response as a function of the input torque, as well as the DTE steady state time history at constant input pinion torque of $T_{s}=60.63 \mathrm{Nm}$ (corresponding to $81 \mathrm{~km} / \mathrm{h}$ steady state cruising velocity of the vehicle). These operating conditions have been chosen for the present analysis, since: (a) they represent the cruising velocity of typical light trucks on highways and (b) in terms of their DTE response these conditions correspond to the region after the $1^{\text {st }}$ primary resonance where no vibro-impact phenomena due to teeth separations occur (Figure 4). 

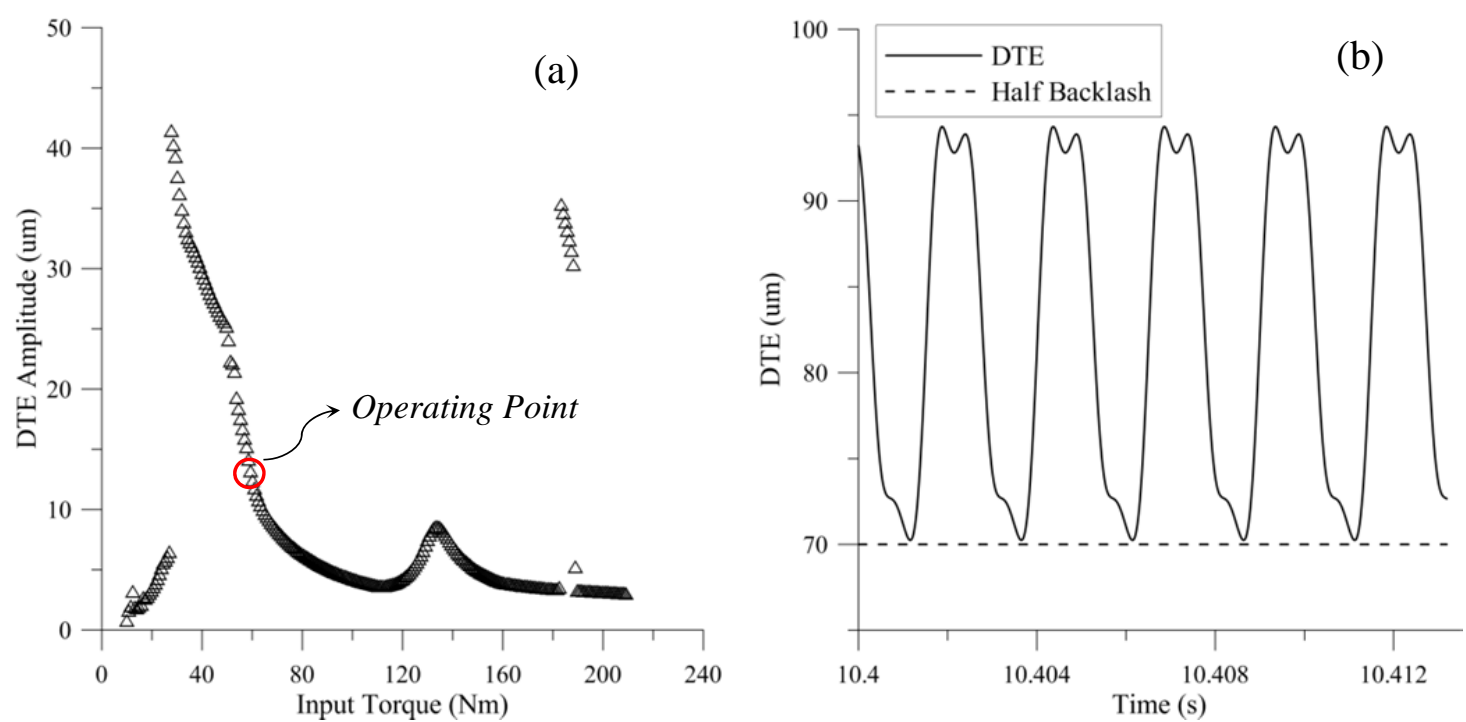

Figure 4: DTE response (a) amplitude as a function of the input torque and (b) time history at $T_{s}=60.63 \mathrm{Nm}$

Although the DTE response is strongly influenced by the input torque, the static transmission error $e$ is assumed to be load-independent. This observation was noted for moderate applied torques (greater than $\sim 20 \mathrm{Nm}$ ) according by Karagiannis ${ }^{33}$, where the TCA of similar hypoid gear pairs was examined. As it can be observed in figure $4 \mathrm{a}$, for $T_{S} \approx 27 \mathrm{Nm}$ (near the primary resonance), the steady state amplitude of DTE exhibits a jump behaviour (non-linear gear dynamics). This is due to the effect of backlash (geometric) non-linearity ${ }^{23,34}$. When operating within the vicinty of this region, teeth separation may occur (depending on system damping and any fluctuations of the external excitations). This leads to teeth vibro-impact phenomena ${ }^{23,}{ }^{34}$. Nevertheless, the focus of the present study is on the lubrication analysis of regions without teeth separation.

Table 2. Values of the parameters of the gear dynamics model.

\begin{tabular}{|c|c|}
\hline Parameter & Value \\
\hline$\left.I_{p}\left(k_{g m}\right)^{2}\right)$ & $1.389 \cdot 10^{-3}$ \\
\hline$I_{g}\left(k g m^{2}\right)$ & $2.887 \cdot 10^{-2}$ \\
\hline$I_{s}\left(\mathrm{kgm}^{2}\right)$ & $1.2502 \cdot 10^{-2}$ \\
\hline$I_{w}\left(k g g m^{2}\right)$ & 0.25986 \\
\hline$k_{t}(N m / r a d)$ & 797210 \\
\hline$c(N s / m)$ & 4378 \\
\hline$c_{t 1}(\mathrm{Nms} / \mathrm{rad})$ & 15 \\
\hline$c_{t 2}(\mathrm{Nms} / \mathrm{rad})$ & 15 \\
\hline$r_{w}(m)$ & 0.32 \\
\hline $\boldsymbol{m}_{v}(\boldsymbol{k g})$ & 1000 \\
\hline$f_{r}(-)$ & 0.008 \\
\hline$a(d e g)$ & 0 \\
\hline$c_{a}(-)$ & 0.5 \\
\hline$A_{f}\left(m^{2}\right)$ & 2.958 \\
\hline$\rho\left(k g / m^{3}\right)$ & 1.2 \\
\hline$b(\mu m)$ & 70 \\
\hline$g\left(m / s^{2}\right)$ & 9.81 \\
\hline
\end{tabular}

The varying flank load during a gear meshing cycle is illustrated in figure 5 with the corresponding velocities along the direction of entraining motion and in the side-leakage direction, respectively. 

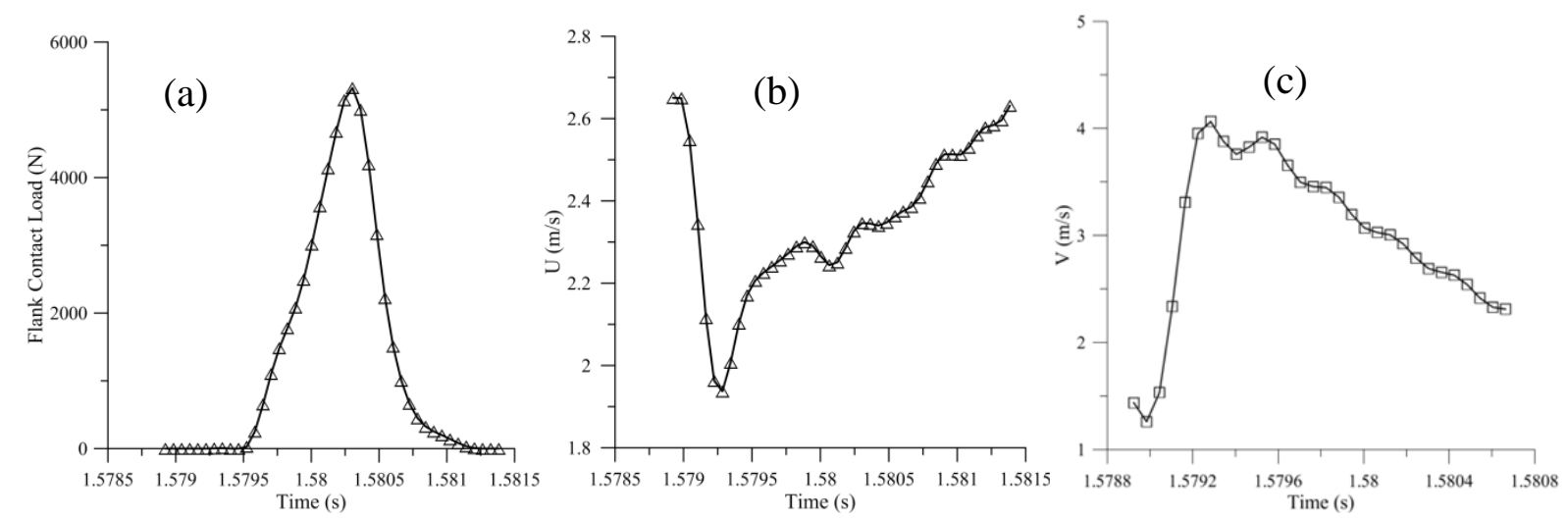

Figure 5: Flank contact load (a), entraining velocity along the direction of entraining motion (b) and entraining velocity along the side leakage direction (c)

It can be seen that the flank load is initially quite low at the beginning of the meshing cycle with relatively high entraining velocities. The same is true of a pair of teeth separating at the end of a typical meshing cycle. This means that the classic EHL theory does not hold for the start and at the end of the meshing cycle. In fact, this is illustrated in the Greenwood chart for a full meshing cycle, indicating the changing nature of the regime of lubrication (figure 6) from iso-viscous rigid (hydrodynamic) through to highly loaded hard-EHL (viscous elastic) conditions. Each of the points within the red circle represents a point in the meshing cycle (Table 3). The values of $G_{e}$ and $G_{v}$ parameters are calculated as ${ }^{35}$ :

$$
\begin{aligned}
& G_{e}=\frac{W^{* 8 / 3}}{U^{* 2}} \\
& G_{v}=\frac{G^{*} W^{* 3}}{U^{* 2}}
\end{aligned}
$$

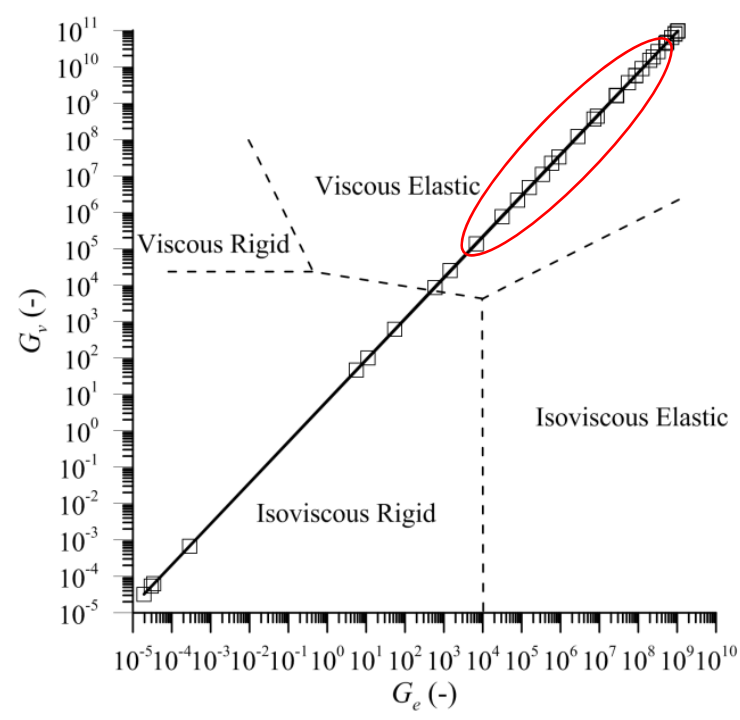

Figure 6: Meshing points on the Greenwood $\operatorname{chart}^{35}$ (region of interest within the red circle)

As shown in figure 6, for the points corresponding to the beginning of the meshing cycle, the classic hydrodynamic lubrication theory (iso-viscous rigid) can be used. However, as the load increases, the contact pressures rise as well as the localised elastic deflection of the mating surfaces, inducing a piezo-viscous response of the lubricant. The present study focuses on the piezo-viscous elastic (EHL) segment of the meshing cycle. Nine points are studied and their central and minimum film thickness values are predicted through numerical analysis. Table 3 summarizes the points of the meshing cycle studied along with the corresponding contact conditions, which depends on the value of the input torque, $T_{s}$. As an indication of the size of the contact footprint with respect to the flank size, the ratio of the elliptical contact footprint major axis to the gear teeth flank face-width remains in the range of 0.16-0.38. 
Table 3. Points investigated along the meshing cycle.

\begin{tabular}{cccccc}
\hline Point & $\mathbf{W}(\mathbf{N})$ & $\mathbf{U}(\mathbf{m} / \mathbf{s})$ & $\mathbf{V ~ ( m / s )}$ & $\mathbf{R z x ~ ( m / s )}$ & Rzy (m/s) \\
\hline $\mathbf{1}$ & 652.14 & 2.240 & 3.655 & 0.0170 & 1.198 \\
$\mathbf{2}$ & 1778.11 & 2.289 & 3.447 & 0.0179 & 1.222 \\
$\mathbf{3}$ & 3016.08 & 2.265 & 3.069 & 0.0183 & 1.280 \\
$\mathbf{4}$ & 4679.21 & 2.286 & 2.922 & 0.0191 & 1.299 \\
$\mathbf{5}$ & 5142.83 & 2.326 & 2.790 & 0.0196 & 1.302 \\
$\mathbf{6}$ & 5323.86 & 2.346 & 2.690 & 0.0199 & 1.310 \\
$\mathbf{7}$ & 5005.89 & 2.344 & 2.656 & 0.0200 & 1.320 \\
$\mathbf{8}$ & 4198.77 & 2.340 & 2.628 & 0.0201 & 1.330 \\
$\mathbf{9}$ & 463.45 & 2.448 & 2.202 & 0.0224 & 1.329 \\
\hline
\end{tabular}

\section{EHL pressure and film thickness}

Figure 7 illustrates the central contact section (for $Y=0$ in figure 3) pressure distribution for the conditions described in table 3. The corresponding dry (Hertzian) pressure distribution is also plotted in each case. This shows that the distributions encountered at the beginning and at the end of the meshing cycle deviate from Hertzian conditions owing to the relatively low contact loads.
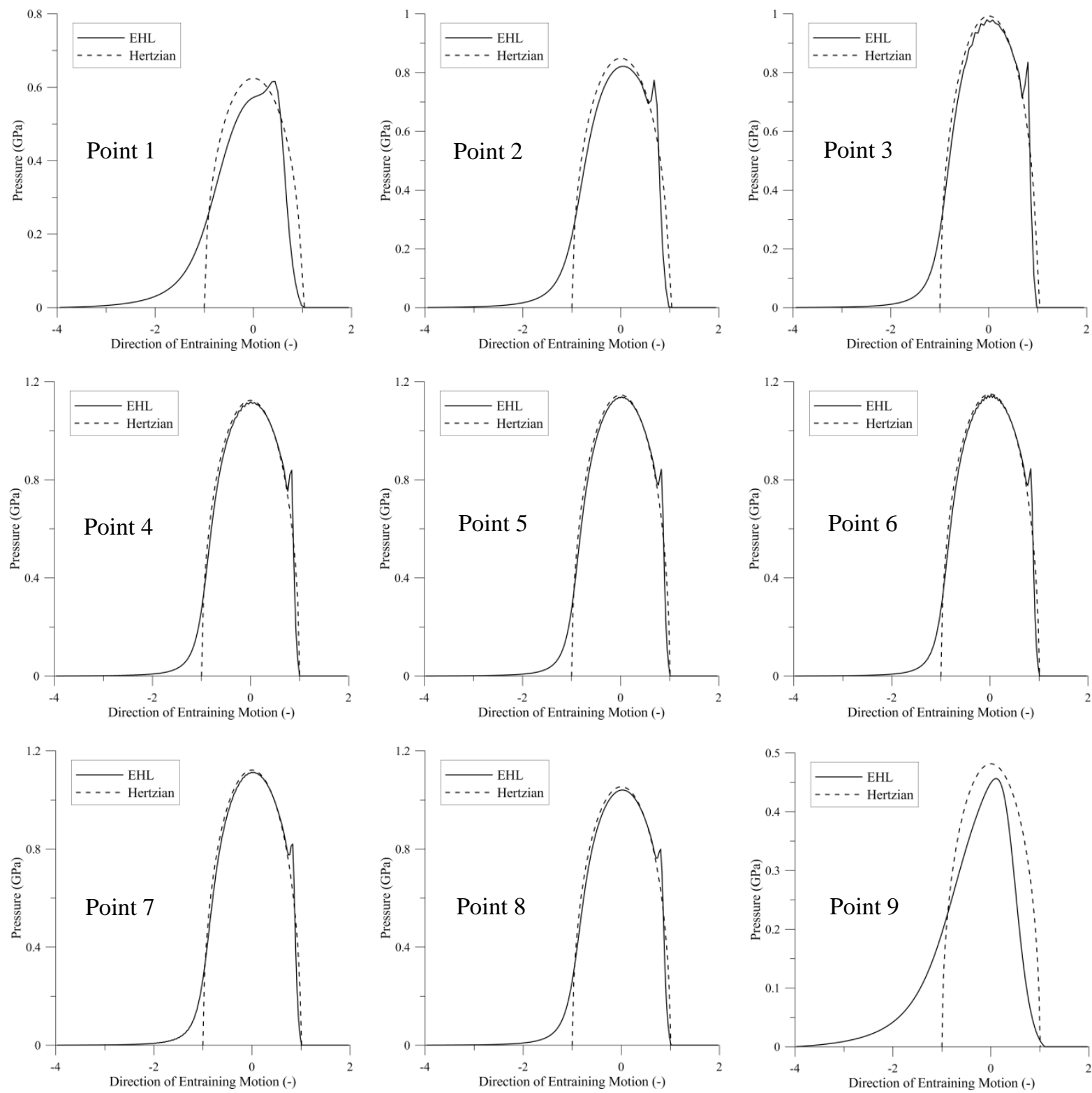

Figure 7: Central contaxct pressure profiles for the points of the meshing cycle under examination 
The deviation from the Hertzian condition under EHL is due to the gradual lubricant pressure building up in the inlet trail and the pressure spike at the contact exit. The corresponding lubricant film thickness contours for all the 9 meshing points are shown in figure 8.
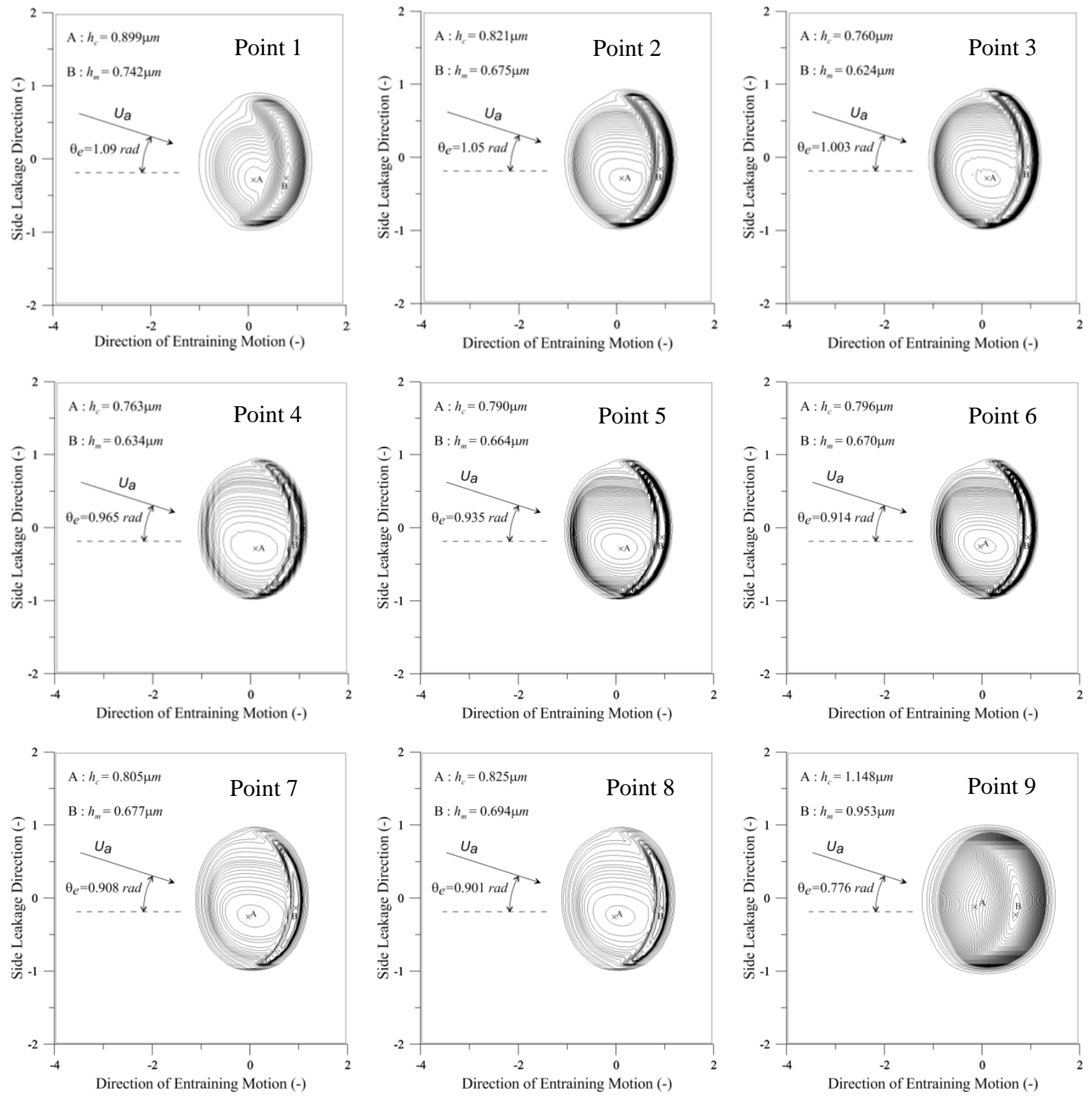

Figure 8. Film thickness contours for the points of the meshing cycle under examination.

The characteristic horse-shoe minimum film thickness constriction is observed at the rear of the Hertzian contact region. This region loses its poignancy with a reducing contact load. The exit constriction of the film thickness is displaced closer to the outlet with an increasing contact load, while the magnitude of the entraining and the side-leakage velocities remain almost the same for all the points examined (as indicated in table 3). The side leakage component of the entraining velocity causes an asymmetry in the film thickness contours. These are expected outcomes as already shown by Jalali-Vahid et al. ${ }^{36}$. It is also observed that, due to this asymmetry in the film thickness distribution, the point of minimum film thickness does not lie on the centre of the contact (for $Y=0$ according to figure 3 ), but is shifted towards the direction of the side leakage flow.

A comparison between the values of the central and minimum film thickness obtained numerically and the corresponding values determined using the Chittenden-Dowson equations ${ }^{37}$ (33) - (34) is presented in figure 9. Reasonable agreement is noted although the Chittenden-Dowson equations ${ }^{37}$ are extrapolated equations of numerical results, assuming a fully flooded inlet. 


$$
\begin{aligned}
& h_{c e n}=4.31 R_{z x} U_{e}{ }^{0.68} G^{0.49} W_{e}^{-0.073}\left\{1-e^{-1.23\left(\frac{R_{s}}{R_{e}}\right)^{2 / 3}}\right\} \\
& h_{\text {min }}=3.68 R_{z x} U_{e}{ }^{0.68} G^{0.49} W_{e}-0.073\left\{1-e^{-0.67\left(\frac{R_{s}}{R_{e}}\right)^{2 / 3}}\right\}
\end{aligned}
$$

Furthermore, the inlet boundary at the fully-flooded/starved boundary position is compared with the starvation boundary of Hamrock and Dowson ${ }^{38}$. For all the points examined, the starvation boundary is located at a distance of $2 b_{h}-3 b_{h}$ from the centre of the contact ellipse and along the direction of entraining motion. It should be noted that the theory behind the calculation of this boundary position ${ }^{38}$ does not take into account the presence of angled flow lubricant entrainment. Equation (35) is used in order to calculate the fullyflooded/starved inlet boundary condition ${ }^{38}$.

$$
X_{i n, f / s}=b_{h}\left\{1+3.06\left[\left(\frac{R_{z x}}{b_{h}}\right)^{2}\left(\frac{h_{c e n}}{R_{z x}}\right)\right]^{0.58}\right\}
$$

The magnitude of the side leakage component of the flow can influence the inlet meniscus position, which may have consequences on the fully-flooded/starved boundary position predicted by the existing theory. In order to prevent the effect of starvation on the numerical results, an inlet distance of $4 b_{h}$ was set throughout the analysis (figure 3). Furthermore, the Chittenden-Dowson equations were extrapolated for conditions, best suited from light to medium contact loads and significantly lower velocities of entraining motion for the lubricant.
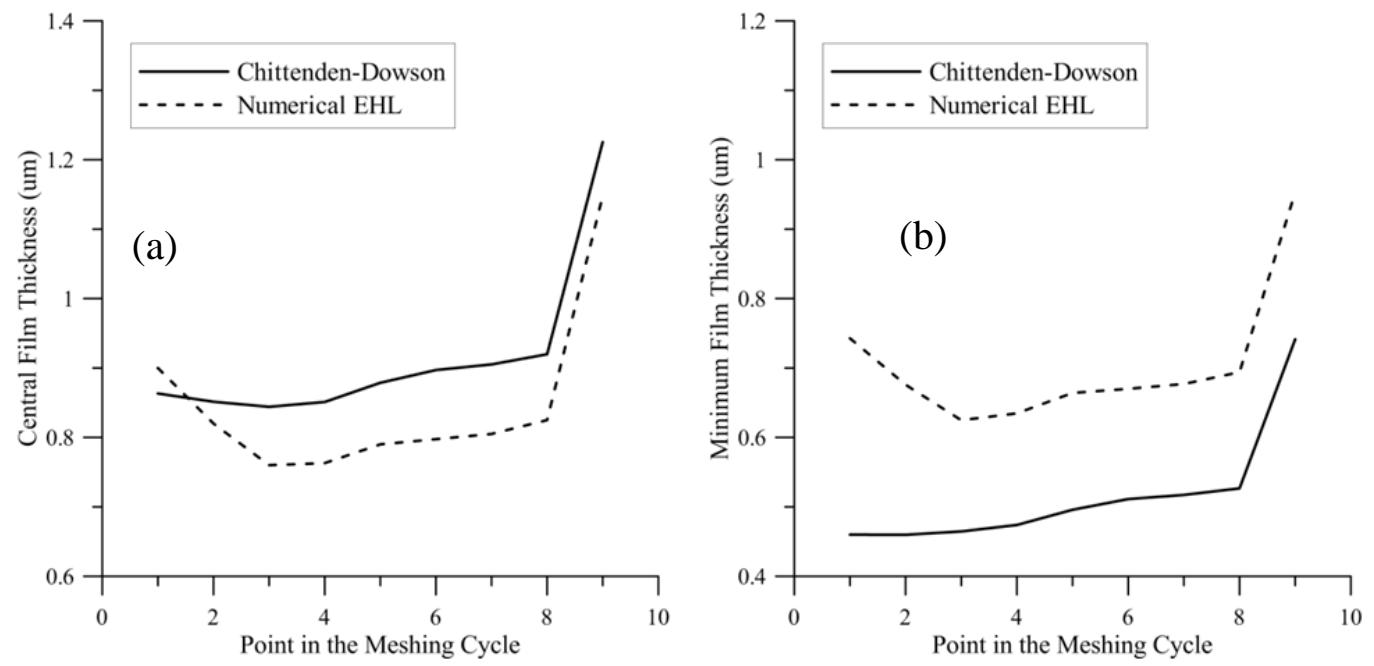

Figure 9: Central (a) and minimum (b) film thickness for the points examined

\section{Sub-surface stress field}

Aside from the gradual wear of the teeth contacting surfaces, which is a function of the regime of lubrication, the eventual useful life of gearing is due to the repetitive loading of their mating teeth, eventually culminating in fatigue failure. There have been many studies with regard to the underlying mechanisms which may affect the fatigue life of the contacting surfaces under application of normal loads and tangential traction. Depending on the kinematics of the contacting surfaces, their material properties and operating conditions, a host of failure criteria have been proposed in the literature. These include the distortion energy hypothesis, also 
known as the von Mises criterion, and the maximum shear stress hypothesis, also referred to as the Tresca criterion. These criteria put emphasis on particular mechanisms, thus certain components of the sub-surface stress field. Broszeit et al. ${ }^{39}$ proposed the study of contacting materials' stressing using the equivalent stress hypothesis, $\sigma_{e}$, first stated by Huber ${ }^{40}$. This hypothesis takes into account all the direct and shear stress components of the sub-surface stress field. The alternating shear stress field underneath the contact footprint, $\tau_{z x}$ causes the sub-surface layers to repeatedly shear in one direction and then in the opposite sense. The repetitive shearing of the sub-surface layers is favoured by many to be the main underlying mechanism affecting the ultimate useful life of bearings and gears ${ }^{5,30,41}$. The equivalent stress with the alternating shear stress hypothesis is $\sigma_{e}=2\left|\tau_{\text {zxmax }} / P_{h}\right|^{32}$, where the amplitude of $\sigma_{e}$ is $\approx 0.5$ and remains approximately the same with additional surface traction even when the effect of the viscous traction is taken into account ${ }^{30}$. Under elastohydrodynamic elliptical point contact conditions, the presence of the pressure spike at the contact exit induces a localised sub-surface stress field of its own which reduces the symmetry of the reversing orthogonal shear stress field ${ }^{5,32}$ both in magnitude and depth of the maximum isoclines. These observations are all evident in the results shown in figure 10 ( $P_{h}$ indicates the maximum equivalent Hertzian pressure in the contact). As noted, there is only a marginal change in the sub-surface field with the inclusion of traction, which in this study corresponds to the viscous friction due to lubricant shearing (neglecting the contribution of asperity friction). The conjunctional viscous friction force is calculated, assuming lubricant Newtonian shear characteristics. Although this is not usually the case for the majority of fully formulated axle fluids, which exhibit shear thinning behaviour, the Newtonian assumption overestimates the viscous shear stress in the contact. The predictions, therefore, provide an over-estimate for viscous shear stress. Johns-Rahnejat ${ }^{32}$ notes that the orthogonal shear stress field is quite sensitive to the contact footprint ellipticity, with large aspect ratios greater than 16 yielding the double amplitude of $\sigma_{e} \approx 0.5$ which is the case in the current analysis.
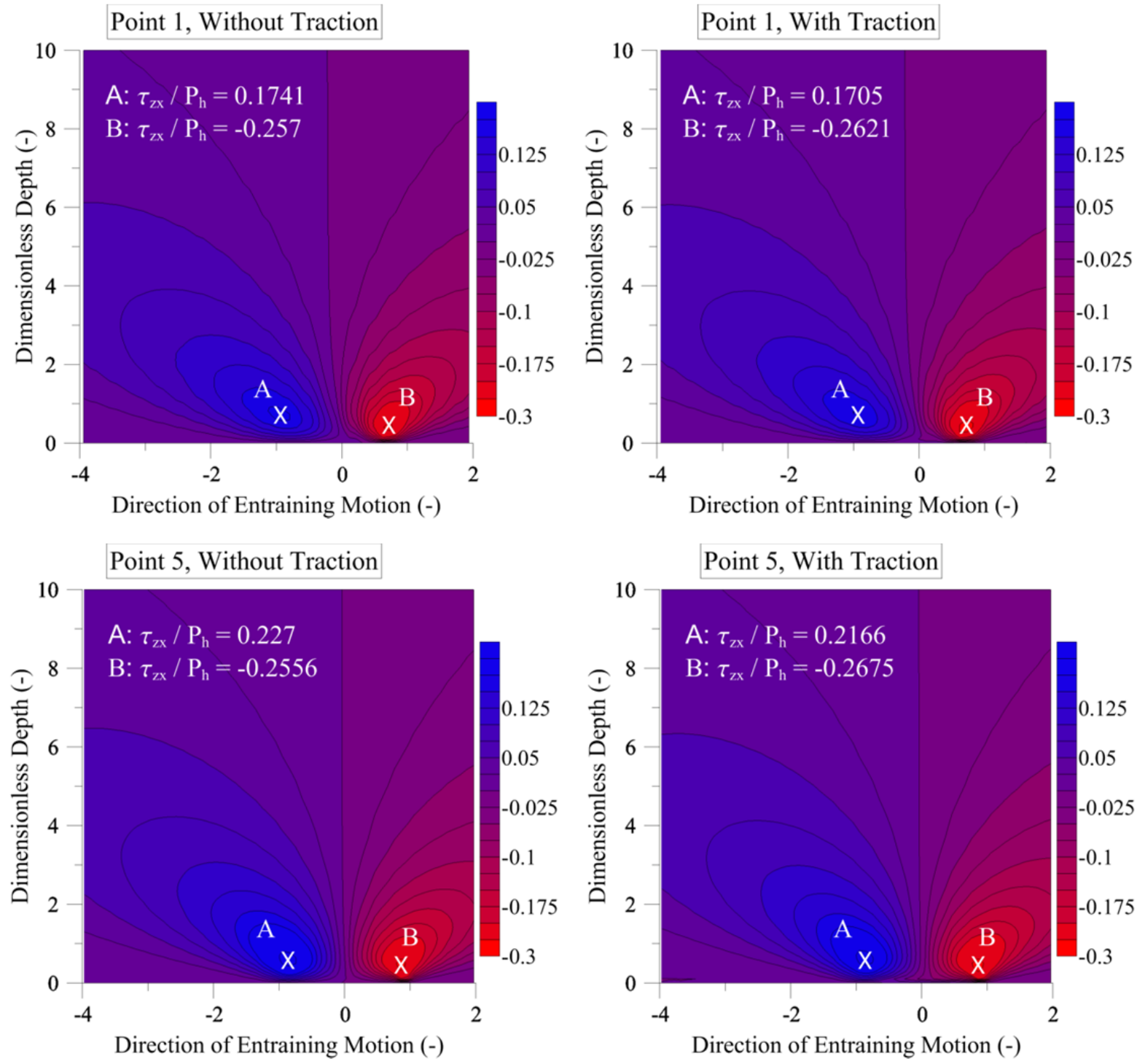

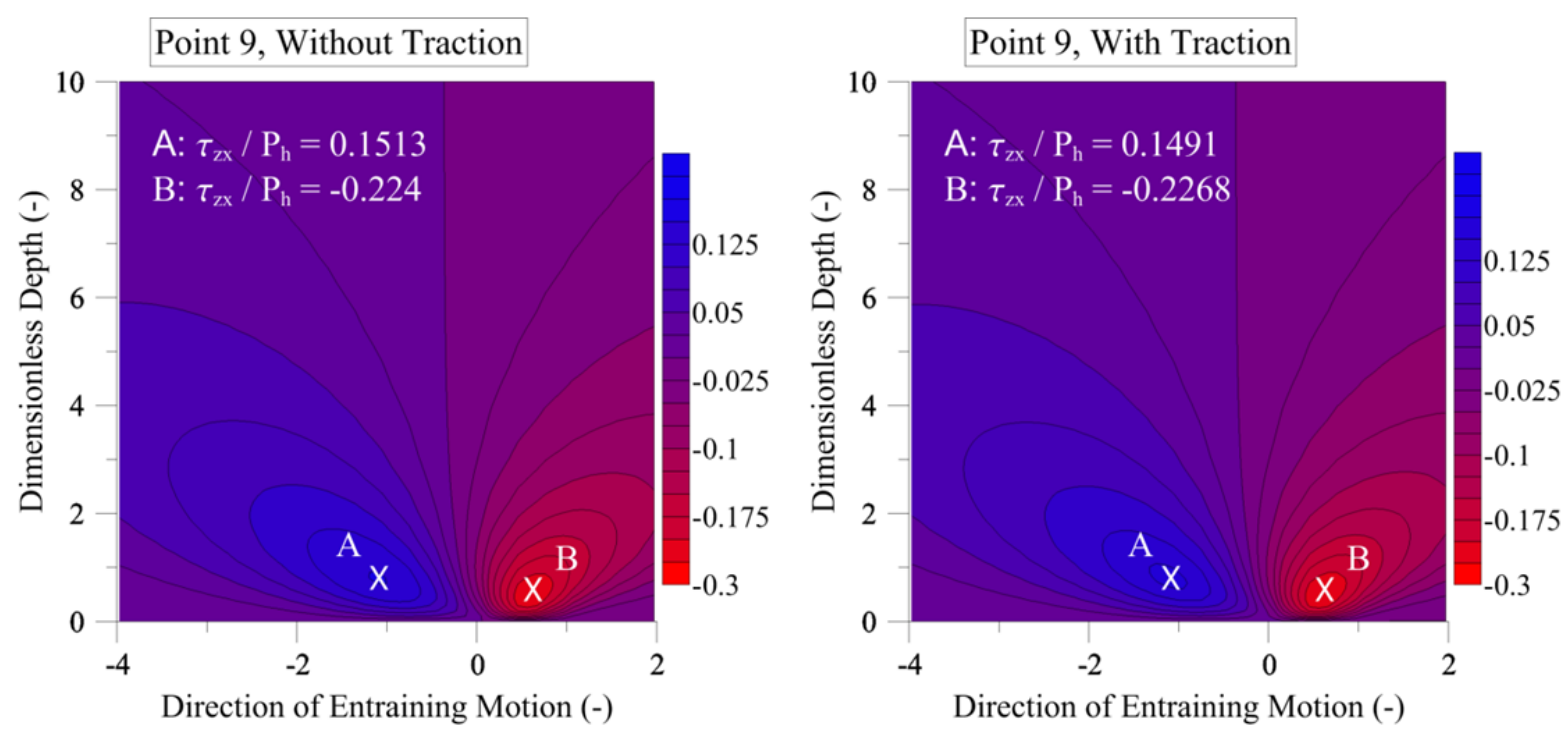

Figure 10: Orthogonal reversing shear stress distribution at points 1, 5 and 9 of the meshing cycle (with and without viscous traction)

The reversing orthogonal shear stress fields for points 1 and 9; at the beginning and the end of the meshing cycle have equivalent stress values $\sigma_{e}<0.5$ which are slightly deviant from the Hertzian conditions and in line with the results shown in the Greenwood chart of figure 6. The sub-surface predictions made here are based on a 2dimensional field. It would be necessary to extend this into a 3-dimensional bulk sub-surface analysis in order to include a detailed fatigue life analysis of the distressed contacting surfaces.

\section{Conclusions}

An isothermal tribo-dynamics analysis of hypoid gear pairs has been presented in this paper. The initial analysis shows that during a typical meshing cycle the regime of lubrication in the teeth pair contact is subject to transience, commencing from iso-viscous rigid conditions through to elastohydrodynamic conditions and culminating in iso-viscous rigid conditions at the onset of tooth separation, which coincides with the end of the meshing cycle. This is corroborated with the use of Greenwood chart. The TCA combined with the gear dynamics model, result in the determination of the surface velocities of the meshing teeth along the major and the minor axes of the Hertzian elasto-static contact ellipse throughout the meshing cycle. This indicates significant side-leakage flow in and out of the contact domain along the major axis of the elliptical contact footprint. Therefore, the angled flow entrainment needs to be taken into account as is the case in this paper. The investigation of the sub-surface stress field, induced by the EHL pressure distribution, also shows the transient nature of the contact dynamics with the reversing orthogonal shear stresses complying with the double amplitude for the equivalent stress value, conforming fairly closely to that of Hertzian line contact condition for the elliptical contact footprint of high aspect ratio. The effect of asymmetry caused by the pressure spike at the rear of the contact on the sub-surface stress field is noted, although this is rather marginal due to the reduced magnitude of the generated pressure spike. Another important observation is that the reduced size of pressure spike heralds deviation of elastohydrodynamic conditions from fully flooded conditions, even though an inlet distance of $4 b_{h}$ was imposed. This is due to the fact that the component of the side leakage velocity causes a subsequent change of the position of the inlet meniscus towards the edges of the computational domain (for $Y= \pm 1.5 a_{h}$ ) which may induce starvation of the lubricant in the conjunction. Future research could yield more realistic results regarding the lubricant film thickness distribution, as well as the distribution of the sub-surface stresses, when the effect of the non-Newtonian shear thinning response of the lubricant with high shear rates can be applied. Furthermore, considering the effect of flank friction on the equations of gear dynamics can also improve the accuracy of the results and predict the contact load which should be supported by the lubricant film.

\section{Acknowledgements}

The authors would like to express their gratitude to Lubrizol Ltd. for its financial support of the research project. 


\section{References}

1. $\quad$ Stadtfeld HJ, Gaiser U. The Ultimate Motion Graph. J Mech Des. 2000;122(September):317-322.

2. $\quad$ Simon V. Optimal Tooth Modifications in Hypoid Gears. J Mech Des. 2005;127(4):646.

3. Simon V V. Design and Manufacture of Spiral Bevel Gears With Reduced Transmission Errors. J Mech Des. 2009;131(4):041007.

4. Mohammadpour M, Theodossiades S, Rahnejat H, Kelly P. Transmission efficiency and noise, vibration and harshness refinement of differential hypoid gear pairs. Proc Inst Mech Eng Part K: J Multi-body Dyn., 228(1), 2014,pp. 19-33

5. Johns-Rahnejat, P. M., and R. Gohar. "Point contact elastohydrodynamic pressure distribution and subsurface stress field." Tri-Annual Conference on Multi-Body Dynamics: Monitoring and Simulation Techniques. 1997.

6. Litvin FL, Gutman Y. Methods of Synthesis and Analysis for Hypoid Gear-Drives of "Formate" and "Helixform" (Part 1. Calculation for Machine Settings for Member Gear Manufacture of the Formate and Helixform Hypoid Gears). J Mech Des. 1981;103(January 1981):83-88.

7. Litvin FL, Gutman Y. Methods of Synthesis and Analysis for Hypoid Gear-Drives of "Formate" "Helixform ", Part 2. Machine Setting Calculations for the Pinions of Formate and Helixform Gears. J Mech Des. 1981;103(January):89-101.

8. Litvin FL, Gutman Y. Methods of Synthesis and Analysis for Hypoid Gear-Drives of Formate" and Helixform’, Part 3. Analysis and Optimal Synthesis Methods for Mismatch Gearing and its Application for Hypoid Gears of Formate" and Helixform". J Mech Des. 1981;103(January):102-110.

9. Karagiannis I, Theodossiades S, Rahnejat H. On the dynamics of lubricated hypoid gears. Mech Mach Theory. 2012;48:94-120.

10. Grubin I. Contact stresses in toothed gears and worm gears. CSRI Technol Mech Eng. 1949;Book 30.

11. Gohar R. Elastohydrodynamics. Imp Coll Press. 2001;2nd Edition.

12. Kolivand M, Li S, Kahraman a. Prediction of mechanical gear mesh efficiency of hypoid gear pairs. Mech Mach Theory. 2010;45(11):1568-1582.

13. Simon V. Influence of machine tool setting parameters on EHD lubrication in hypoid gears. Mech Mach Theory. 2009;44(5):923-937.

14. Li S, Kahraman a. A tribo-dynamic model of a spur gear pair. J Sound Vib. 2013; 332(20): 4963 - 4978.

15. Li S. A thermal tribo-dynamic mechanical power loss model for spur gear Pairs. Tribol Int. 2015; 88:170-178.

16. Mohammadpour M, Theodossiades S, Rahnejat H. Elastohydrodynamic lubrication of hypoid gear pairs at high loads. Proc. Inst. Mech. Eng, Part J: J Eng Tribol. 2012;226(3):183-198.

17. Mohammadpour M, Theodossiades S, Rahnejat H, Saunders T. Non-Newtonian mixed elastohydrodynamics of differential hypoid gears at high loads. Meccanica. 2013;49(5):1115-1138. 
18. Wang J, Lim TC, Li M. Dynamics of a hypoid gear pair considering the effects of time-varying mesh parameters and backlash nonlinearity. J Sound Vib. 2007;308(1-2):302-329.

19. Wang J, Lim TC, Li M. Time-Varying Non-Linear Dynamics of a Hypoid Gear Pair for Rear Axle Applications. SAE Tech Pap. 2007.

20. Schwarz B, Richardson M. Proportional Damping from Experimental Dara. Top Modal Anal. 2014;7:179-186.

21. Mostofi A. The Incorporation of Damping in Lumped-parameter Modelling Techniques. Proc Inst Mech Eng., Part K: J Multi-body Dyn. 1999;213:11-17.

22. Karagiannis I, Theodossiades S, Rahnejat H. The Effect of Vehicle Cruising Speed on the Dynamics of Automotive Hypoid Gears. SAE Technical Paper 2012-01-1543, 2012, doi:10.4271/2012-01-1543..

23. Karagiannis I, Theodossiades S. An Alternative Formulation of the Dynamic Transmission Error to Study the Oscillations of Automotive Hypoid Gears. J Vib Acoust. 2013;136(1):1-12.

24. Vijayakar SM. Tooth Contact Analysis Software: Calyx. Adv Numer Solut Hilliard, OH. 1998.

25. Mohammadpour M, Theodossiades S, Rahnejat H. Multiphysics Investigations on the Dynamics of Differential Hypoid Gears, J. Vib. Acoust. 2014;136(4), 041007.

26. Yin C, Yang P, Tan H, Wang J. Thermal elastohydrodynamic lubrication of starved elliptical contacts. Tribol Int. 2009;42(6):964-974.

27. Roelands C. Correlational Aspects of the Viscosity-Temperature Pressure Relationship of Lubricating Oils. 1966;(April):495.

28. Houpert L. New results of traction force calculations in elastohydrodynamic contacts. $J$ Tribol. 1985;107(2):241-248.

29. Dowson D, Higginson GR. Elasto-hydrodynamic Lubrication. Int Ser Mater Sci Technol. 1977;Pergamon P.

30. Gohar R, Rahnejat H. Fundamentals of Tribology, Imperial College Press, 2008, London.

31. Johnson KL. Contact Mechanics, Cambridge University Press, 1985.

32. Johns-Rahnejat PM. Pressure and Stress Distribution under Elastohydrodynamic Point Contacts. PhD Thesis, Imperial College,University of London. London, 1988.

33. Karagiannis I. Tribo-dynamic Analysis of Hypoid Gear Pairs in Automotive Differentials. PhD Thesis, Loughborough University 2013.

34. Kahraman A, Singh R. Non-Linear Dynamics of a Spur Gear Pair. J Sound Vib. 1990;142:49-75.

35. Greenwood JA. Film thicknesses in circular elastohydrodynamic contacts. Proc Inst Mech Eng Part C Mech Eng Sci. 1988;202:11-17.

36. Jalali-Vahid D, Rahnejat H, Gohar R, Jin ZM. Prediction of Oil-Film Thickness and Shape in Elliptical Point Contacts under Combined Rolling and Sliding Motion. Proc Inst Mech Eng Part J: J Eng Tribol. 2000;214:427-437.

37. Chittenden RJ, Dowson D, Dunn JF, Taylor CM. A Theoretical Analysis of the Isothermal Elastohydrodynamic Lubrication of Concentrated Contacts. I. Direction of Lubricant Entrainment 
Coincident with the Major Axis of the Hertzian Contact Ellipse. Proc R Soc A Math Phys Eng Sci. 1985;397(1813):245-269.

38. Hamrock BJ, Dowson D. Isothermal Elastohydrodynamic Lubrication of Point Contacts Part IV Starvation Results. J Lubr Technol. 1977;(January):15-23.

39. Broszeit E, Zwirlein O. Internal Stresses and Their Influence on Material Stresses in Hertzian Contacts Calculations With Different Stress Hypotheses. J Tribol. 1986;108(July):387.

40. Huber MT. Zur Theorie der Beruhrung Fester Elastscher Korper. Ann Phys. 1904;Ed. 14.

41. Kannel JW, Tevaarwerk JL. Subsurface stress evaluations under rolling/sliding contacts. Trans Am Soc Mech Eng. 1984; 106. 